\title{
Energy safety of the region on the example of the city of Sevastopol
}

\author{
Elena Piskun ${ }^{1, *}$, Vladimir Khokhlov ${ }^{1}$, and Lidiya Guryanova ${ }^{2}$ \\ ${ }^{1}$ Sevastopol State University, 299053 Sevastopol, Russia \\ ${ }^{2}$ Simon Kuznets Kharkiv National University of Economics, Economic Cybernetics and \\ System Analysis Department, 61166 Kharkiv, Ukraine
}

\begin{abstract}
Energy safety problems arise and require solutions at the macro and meso levels. Energy security contributes to the extensive and intensive development of industry and services, the creation of comfortable living conditions for the population of the region. At the same time, there is a problem of quantitative assessment of the energy security of the region. The purpose of this study is to find an indicator reflecting the state of regional energy security and its impact on the economy. The proposed methodology makes it possible to determine: the supply of fuel and energy resources, taking into account the availability of the resource and the level of its consumption; the level of energy security based on changes in the provision of energy resources, linked to fluctuations in the gross regional product. According to the studies carried out according to the developed methodology and based on the statistical data of the city of Sevastopol, the level of energy security of the region is positive, despite the negative values of the provision of energy resources (except for 2020). At the same time, the gross regional product shows growth. It can be assumed that subsequent periods of the city's functioning will be characterized by economic growth. Further research by the authors will be aimed at predicting both the energy and economic security of the region.
\end{abstract}

\section{Introduction}

Energy security, along with economic, social, environmental, industrial, informational, scientific and technical, cultural, food security, is a structural element of the region's security. From our point of view, energy security ensures the implementation of other types of territory security, as it contributes to the security of both the life of citizens and the activities of business structures in all sectors of the economy.

"Nowadays energy security studies has shifted from a classic approach and become an interdisciplinary field" [1]. In various regions of the world, "Develop policies based on sound science and realistic economic, national security, and environmental needs to make decisions that are timely, consistent, and coordinated with energy security, economic, and environmental objectives" should be implemented [2]. "Energy security is no longer a single-dimensional concept, but a synthetic term, and the technological, environmental,

*Corresponding author: lenapiskun@ mail.ru 
social, even political aspects can be improved to enhance energy security" [3]. "Nations possessing conventional fuels are willing to use them for enhancing their energy security under an all-of-the-above strategy, which implies also the expansion of renewable energy installations, as in the cases of the United States and China, while those ones that lack of fossil resources tend to compensate this hardship by relying deeper on renewable energy and reducing their energy consumption, as the European countries do" [4]. Speaking of countries around the world, "European countries were found to be at the top of the global energy security performance (ESP) rankings, while African countries were at the bottom. In addition, Switzerland remained at the top of the ESP ranking for 21 years. Australia, the UK, and Ireland, all belonged to both the most progressive group and the group with the highest ESP" [5]. In China, "until now, energy security is in the recovery period. According to the similarity of the energy security function curve, the 30 provinces can be divided into three categories: Leading area, Medium area, and Backward area" [6]. Having studied the experience of individual regions of the world, the authors note that "Azerbaijan, Iran, Kazakhstan made significant progress in energy security since 1990, while energy security indicators in Russia, Uzbekistan, and Turkmenistan regressed. Iran has a leading position in energy security performance, while Uzbekistan and Turkmenistan have the lowest level of the energy security indicators compare to other region countries" [7]. "If the average annual development rate of the Russian economy is below $4 \%-5 \%$, it will be impossible to reach the main target of the Energy Strategy of the Russian Federation until 2035, which is the reduction of energy intensity of the gross domestic product (GDP) in 2035 by 34\% compared to 2015" [8]. In view of the vastness of the territory of the Russian Federation, the regions have specific economic activities and energy security problems inherent in them. In particular, "we examined energy supply problems in the example of the Tuva Republic, the Russian region with vast isolated areas and high prices for energy" [9]. "Nowadays, it is relevant to consider changes in the structure of the fuel and energy balance of industrial regions and the availability of imported fuel and energy resources, especially in the areas that lack energy sources" [10].

After reunification with Russia for Crimea and Sevastopol, the problems of energy security acquired particular importance. The terrorist events of November 2015, when the pylons on all four power lines that supplied Crimea and Sevastopol were blown up, zeroed the voltage in the grids of the new federal district of the Russian Federation. Thanks to the power bridges laid from the Krasnodar Territory, the power supply was mainly restored, and with the commissioning of two thermal power plants, there was even a surplus of electrical energy. Nevertheless, monitoring and analyzing the energy security of both Crimea and Sevastopol is an urgent task.

There are a fairly large number of definitions of the concept of "energy safety". V.V. Morozov interprets energy security as a reliable and uninterrupted supply of electrical and thermal energy to consumers [11]. V.A. Savelyev gives the following definition: "Energy security is a state of protection of vital "energy interests" of an individual, society and region from internal and external threats. These interests boil down to uninterrupted provision of consumers with economically accessible fuel and energy resources of acceptable quality" [12]. These definitions, as well as a number of other definitions of the energy security of the region, for example: "The energy security of the region should be understood as the characteristics of the fuel and energy complex of the region, which determines the ability of this complex, based on the efficient use of internal and external resources, to provide reliable energy supply to economic entities and the population, without prejudice to the economic security of the region" [13], do not indicate the possibility of quantitative measurement of regional energy security. Some possibility of its quantitative assessment is given by L. Gryaznova: "Energy security of a market economy is the provision of the economy with fuel and energy resources at a cost, at which, on the one 
hand, reproduction in the fuel and energy complex sectors is possible, and on the other hand, when in the main sectors of the national the economy produces a positive added value" [14].

We will not give new definitions of this concept, but based on the last definition, we will set as the goal of this study the search for an indicator reflecting the state of regional energy security and its impact on the economy.

\section{Research methodology}

The provision of fuel and energy resources is determined by the availability of the resource and the level of its consumption. Then the indicator reflecting the endowment of a certain resource can be determined as follows:

where $\quad S_{i}$ - safety of the $i$-th resource,

$$
S_{i}=\frac{O_{i}-D_{i}}{D_{i}}
$$

$O_{i}$ - offer of the $i$-th resource,

$D_{i}$ - demand for the $i$-th resource.

Let's distinguish three types of energy resources: electricity, gas and transport fuel. Let us simplify the task as much as possible and assume that technological capabilities make it possible to fill the deficit of one resource by using another, then the total resource endowment can be represented by the additive expression

where $X$ - total energy supply;

$$
X=w_{1} S_{1}+w_{2} S_{2}+w_{3} S_{3}
$$

$S_{i},(i=1,2,3)$ - provision, respectively, 1 - electricity, 2 - gas, 3 - fuel;

$w_{i},(i=1,2,3)$ - weighting factors for which $\sum w_{i}=1$.

The endowment of resources directly affects the rhythm of production processes, as well as the functioning of those sectors of entrepreneurial activity in which added value is produced. Thus, the sufficiency of resources directly determines the positive dynamics of the gross regional product, and together with it - the energy security of the individual, region and society. At the same time, changes in the supply of energy resources, linked to fluctuations in GRP, reflect the level of energy safety:

$$
L E S_{t}=\operatorname{sign}\left\{\Delta X_{t}\right\} \cdot\left|\frac{\Delta Y_{t}}{\Delta X_{t}}\right| ;
$$

where $L E S_{t}-$ Level of Energy Safety for a period of time $t$;

$\Delta Y_{t}$ - change in gross regional product for the period $t$;

$\Delta X_{t}$ - change in energy supply for the period $t$,

$\operatorname{sign}\left\{\Delta X_{t}\right\}-$ sign of change in energy supply (minus or plus).

A positive value (1) corresponds to positive trends in the provision of energy resources, a negative one indicates a lag in the level of resources from their needs.

The situation when the level of the gross regional product falls, i.e. $\Delta Y_{t}<0$, speaks of inefficient use of energy resources, and not of a decrease in energy security.

The LES indicator can be used as an indicator characterizing the energy security of the region.

The value of the $L E S$ indicator for a certain period of time, first of all, depends on the state of resource endowment and the level of gross product achieved during the period, i.e. can be described by the equation:

where $X_{t}$ - energy supply over a period of time $t$;

$$
L E S_{t}=a X_{t}+b Y_{t}+E_{t}
$$

$Y_{t}-$ value of gross regional product for a period of time $t$;

$E_{t}$ - random model residual,

$a, b-$ coefficients with appropriate dimensions. 
The LES indicator indicates the following: by how many monetary units will the gross regional product change (or changed) if the energy supply changes by one percent over a given period of time.

Expression (2) is a regression equation, and its coefficients can be estimated based on statistical data.

\section{Research results}

Table 1 shows statistical, expert and calculated data. In it, the following weights of indicators were used to calculate the total supply of energy resources: $w_{1}=0,5 ; w_{2}=$ 0,$25 ; w_{3}=0,25$. GRP values and its increments are indicated in prices of January 2014 (million rubles).

Table 1. Initial and calculated data on the energy security of the city of Sevastopol.

\begin{tabular}{|c|c|c|c|c|c|c|c|c|}
\hline Year & $S_{1}$ & $S_{2}$ & $S_{3}$ & $X_{t}$ & $\Delta X_{t}$ & $Y_{t}$ & $\Delta Y_{t}$ & \multicolumn{1}{c|}{$L E S_{t}$} \\
\hline 2014 & $-0,10$ & $-0,10$ & 0,00 & $-0,08$ & - & 17501,84 & - & - \\
\hline 2015 & $-0,90$ & $-0,70$ & $-0,30$ & $-0,70$ & $-0,63$ & 25918,84 & 8417,01 & $-13467,21$ \\
\hline 2016 & $-0,30$ & $-0,50$ & $-0,20$ & $-0,33$ & 0,38 & 32182,95 & 6264,11 & 16704,29 \\
\hline 2017 & $-0,25$ & $-0,20$ & $-0,15$ & $-0,21$ & 0,11 & 40784,15 & 8601,20 & 76455,14 \\
\hline 2018 & $-0,20$ & $-0,15$ & $-0,10$ & $-0,16$ & 0,05 & 63143,36 & 22359,20 & 447184,09 \\
\hline 2019 & $-0,05$ & $-0,10$ & $-0,10$ & $-0,08$ & 0,09 & 69205,34 & 6061,98 & 69279,75 \\
\hline 2020 & 0,10 & $-0,10$ & $-0,10$ & 0,00 & 0,08 & 92755,44 & 23550,10 & 314001,35 \\
\hline
\end{tabular}

Estimation of the coefficients (2) using the least squares method gave the following values: $a=141418.90$ (million rubles), $b=3.514$ (dimensionless value).

If in equation (2) the time period tends to zero, then $\Delta X_{t} \rightarrow 0$, then passing to the limit, we obtain the differential equation

The general solution (3) has the form:

$$
Y_{X}^{\prime}=a X+b Y \text {. }
$$

$$
Y(X)=C \cdot e^{b X}-\frac{a}{b} X-\frac{1}{b^{2}}
$$

Substituting the 2014 data in (4) as the initial conditions, we obtain the value of an arbitrary constant: $\mathrm{C}=18918.6$ (million rubles).

It should be noted that equation (4) is a reflection of the processes that took place in Sevastopol from 2014 to 2020, characterized by negative values of the total energy supply. A negative value of $\mathrm{X}$ makes the term positive $-\frac{a}{b} X$, those. Lack of resources leads to an increase in GRP, which is illogical. However, the period under study is characterized by an active overcoming of the deficit of energy resources in the region and, first of all, electricity, which was accompanied by the growth of the regional product. At the same time, the very value of the level of energy security was negative only in 2015 , in other years the $L E S$ took positive values.

For the city of Sevastopol, the excess demand for energy resources over their supply is a stimulating factor for the growth of the gross regional product.

\section{The discussion of the results}

The problem of energy security is relevant all over the world and is the object of disputes between states that are trying to comply with their own, both political and economic interests. Thus, in our work, we studied the German gas market within the framework of international energy cooperation. "The conclusion is that the German government generally 
upholds this concept, although sometimes the consequences are of negative nature, manifested in rising prices, added complexity of international natural gas trade, especially with the largest supplier - the Russian Federation. Using the Bertrand competition model, the article justifies the conditions under which the export of liquefied natural gas is beneficial for the Russian Federation" [15].

Energy security issues are being actualized in those territories that, from the point of view of the world community, are controversial. These territories include the city of Sevastopol and the Republic of Crimea. Ukraine tried to influence the government of the Russian Federation by stopping the power supply of these regions.

On the one hand, the results obtained are somewhat contradictory, but on the other hand, they reflect the specific conditions of the economic development of the city of Sevastopol. Despite the critical situation with electricity in the region, the business sector tried to maintain the existing volumes of production of goods and services. It should be noted that in the most unfavorable year, 2015, from the point of view of electricity supplies, a way out of the situation was found. During this period, both the processing industry and the service sector used generators in their activities to meet the demand for energy resources. In the future, as the construction of energy supply facilities, as evidenced by the data in the table, negative values of energy supply decrease and in 2020 reach zero. This indicates that in modern conditions the studied region is independent from the point of view of the electric power industry.

\section{Conclusions}

In this study, we searched for an indicator reflecting the state of regional energy security and its impact on the economy. The provision of fuel and energy resources is determined by the availability of the resource and the level of its consumption. The assumption was made that technological capabilities make it possible to compensate for the deficit of one resource by using another, then the total resource endowment was represented by an additive expression that takes into account the provision of electricity, gas, and fuel. The provision of resources directly affects the functioning of the branches of the national economy and the energy security of the population. And the sufficiency of energy resources - for the positive dynamics of the gross regional product. At the same time, changes in the supply of energy resources, linked to fluctuations in GRP, reflect the level of energy security.

According to the studies carried out according to the developed methodology and based on the statistical data of the city of Sevastopol, the level of energy security of the region is positive, despite the negative values of the provision of energy resources (except for 2020). At the same time, the gross regional product shows growth. It can be assumed that subsequent periods of the city's functioning will be characterized by economic growth.

Further research by the authors will be aimed at predicting both the energy and economic security of the region.

The reported study was funded by RFBR and Government of the Sevastopol according to the research project № 18-410-920001.

\section{References}

1. T. Jakstas ,Ener. Transf. Tow. Sust., 99 (2020)

2. B.G. Miller, Clean Coal Eng. Techn., 585 (2011)

3. L.Zhang, W. Bai, H.Xiao, J. Ren, Energy, 227 (2021) 
4. S. Fuentes, R. Villafafila-Robles, P. Olivella-Rosell, J. Rull-Duran, S. GalceranArellano, Ren. Ener. Foc., 33, 23 (2020)

5. T.-H. Wu, Y.-F. Chung, S.-W. Huang, Sust.e Ener. Techn. and Ass., 45, (2021)

6. X. Gong, Y.Wang, B. Lin, Energy, 217, (2021)

7. M. Karatayev, S. Res. Pol., 68 (2020)

8. V. A. Tsybatov Econ. of reg., 16(3), 739 (2020)

9. A. N. Asaul, M. A. Asaul, Yu. A. Levin, A. M. Platonov Econ. of reg., 16(3), 884 (2020)

10. L.D. Gitelman, Dobrodey, V.V., M.V. Kozhevnikov, (2020). Econ. of reg., 16(4), 1208

11. V.V. Morozov, Strategic Innovation Management in the Electric Power Industry (Moscow, Alfa-M, 2004)

12. V.A. Savelyev, Methodology for assessing the energy security of regions on the example of the Ivanovo region (Moscow, Energoatomizdat, 2002)

13. V.I. Ryasin, Bulletin of IGEU, 2 (2005)

14. L. Gryaznov, Theses on the energy crisis, www.cogeneration.ru/

15. E.I. Piskun, V.Y. Chaikin, N.A. Nikitin, Int. Conf. on Eff. Prod. and Proc. (2020) 